\title{
Effects of Levetiracetam and Topiramate Monotherapy on Oral Health in Epileptic Children
}

\author{
Mennatallah O. Shata ${ }^{1}$, Hamed M Shatla ${ }^{1}$, Sherine Badawy ${ }^{2}$, Mostafa M Metkees ${ }^{3}$ \\ ${ }^{1}$ Department of Pediatrics, Faculty of Medicine, Ain Shams University, Cairo, Egypt \\ ${ }^{21}$ Department of Pediatric Dentistry, Faculty of Dentistry, Fayoum University, Fayoum, Egypt \\ ${ }^{3}$ Department of Pediatrics, Egyptian Ministry of Health, Egypt \\ *Corresponding author: Mennatallah O. Shata, Mobile: (+20)01006636930, E-Mail: mennahshata@gmail.com
}

\begin{abstract}
Background: Epilepsy is a common neurologic disease in children associated with multiple neurodevelopmental comorbidities or related to adverse drug reactions due to antiepileptic drugs.

Objective: To study the effects of Levetiracetam (LEV) and Topiramate (TPM) monotherapy on oral cavity, to improve oral health care of epileptic children.

Patients and methods: This study was conducted on 60 epileptic children of age group $6-12$ years compared to 30 normal age- and sex-matched controls, 30 children on LEV monotherapy and 30 on TPM monotherapy. All were subjected to full clinical dental examination by a pediatric dental expert.

Results: There was significant increase in plaque index $50 \%$ grade 3 in children receiving antiepileptic medications, the decay-missing-filled (DMF) index was significantly more in children than in epileptic children, $43.3 \%$ of children on antiepileptic having grade 1 Gingival index, while grade 2 gingival enlargements were noticed in $43.3 \%$ and dental hygiene was missed in $76.7 \%$ of children on antiepileptic drugs. Most of the indices were little more with TPM group than LEV group.

Conclusions: Both LEV and TPM affect oral health of epileptic children, which makes regular screening for oral health by a pediatric dental expert necessary to detect early changes and intervene to improve their quality of life.
\end{abstract}

Keywords: Epilepsy, Children, Oral health, Antiepileptic drugs.

\section{INTRODUCTION}

Epilepsy is the most common chronic brain disorder in children. The incidence of epilepsy in children ranges from 41-187/100,000. Higher incidence is reported from underdeveloped countries, particularly from rural areas ${ }^{(\mathbf{1})}$. According to the new International League Against Epilepsy (ILAE) definition of epilepsy, it is a brain disease defined by the following conditions:

(1) two unprovoked (or reflex) seizures occurring more than $24 \mathrm{~h}$ apart; (2) one unprovoked (or reflex) seizure and a probability of further seizures similar to the general recurrence risk (at least 60\%) after two unprovoked seizures, occurring over the next 10 years; and (3) diagnosis of an epilepsy syndrome ${ }^{(2)}$. Efficacy of antiepileptic drugs (AEDs) are often equivalent, hence selection of an AED is often determined by the adverse effects (AEs) ${ }^{(3)}$.

Gingival hyperplasia $(\mathrm{GH})$ is characterized by the overgrowth of gingival sub-epithelial connective tissue and epithelium that develops about 1-3 months after the start of phenytoin (PHT) treatment. Although several studies examined the effects of PHT on oral health, none have studied those of the newer generation of AEDs ${ }^{(4)}$.

Aim of the work was to study effects of Levetiracetam (LEV) and Topiramate (TPM) monotherapy on oral cavity in order to improve oral health care of epileptic children.

\section{SUBJECT AND METHODS}

Study design: A cross-sectional study done at the Pediatric Neurology Clinic and Pediatric Outpatients' Clinic, Children's Hospital, Ain Shams University, Cairo, Egypt during the period from January 2018 to June 2019.

Subjects: The study population was 60 children who were diagnosed epileptics, aging from 6 to 12 years old, participated in this cross-sectional study. They were divided into two groups according to the antiepileptic drug administrated.

Group 1: thirty epileptic patients on Levetiracetam. Group 2: formed of thirty epileptic patients on Topiramate. Thirty healthy age- and sex- cross matched children who were not receiving any antiepileptic drug and were selected from the Outpatient Departments of Pediatrics and Neurology, Faculty of Medicine, Ain Shams University to act as a control.

Inclusion criteria: Epileptic children on regular monotherapy with antiepileptic drugs, (LEV and TPM) taken for at least 3 to 6 months prior to the study along with their medical records. They were examined by the neurologist to document the exact cause of epilepsy and to record the AED that they were taking.

Exclusion criteria: Gingival surgery or periodontal treatment prior to the screening visit, mental retardation and children with systemic diseases 
affecting the gingiva, such as endocrine disorders (e.g. diabetes), hematologic disorders (e.g. thrombocytopenic purpura or leukemia), immunodeficiency states and treatment with drugs known to cause gingival enlargement, such as cyclosporine $\mathrm{A}$ and calcium antagonists.

All patients were subjected to the following: Full history taking including demographic data, name, age, sex, parental consanguinity, and any similar condition in the family. Neurological symptoms including convulsions, mental delay, squint, weakness, lateralization, pupillary reaction to light and developmental history. Full clinical examination including general examination, vital data monitoring and anthropometric measures (weight, height, and BMI). Detailed dental examination done by a pediatric dental expert, all children were examined clinically for dental caries using sterile diagnostic instruments: plane mirrors, sickle explorers No.23, tweezers and cotton rolls under natural light and with the patient sitting on an ordinary upright chair. The gingival conditions of the patients were evaluated by gingival index, dental plaque index and gingival enlargement.

\section{These parameters were graded as follows:}

- Gingival index: Grade 0, normal gingiva; grade 1, mild inflammation, slight change in color, slight edema; no bleeding on palpation. Grade 2, moderate inflammation, hyperemia, edema, and glazing; bleeding on palpation. Grade 3, severe inflammation, marked hyperemia and edema, ulcerations, tendency to spontaneous bleeding ${ }^{(5)}$.

- Plaque index: Grade 0, no plaque in the gingival area. Grade 1, a film of plaque adhering to the free gingival margin and adjacent area of the tooth; the plaque can be recognized only by running a probe across the tooth surface. Grade 2, moderate accumulation of soft deposits within the gingival pocket and on the gingival margin and/or adjacent tooth surface, which can be seen by the naked eye. Grade 3, abundance of soft matter within the gingival pocket and/or on the gingival margin and adjacent tooth surface ${ }^{(6)}$.

- Gingival enlargement: was graded according to the index originally described by Angelopoulos and Goaz (7) and later modified by Miller and Damm ${ }^{(8)}$. The height of gingival tissue was measured from the cement-enamel junction to the free gingival margin. The following grades were scored in six dental points around each tooth: Grade 0, normal gingiva. Grade 1, minimal enlargement $(<2 \mathrm{~mm}$ increase in size) and gingiva covering the cervical third or less of the anatomic crown. Grade 2, moderate enlargement (2-4 $\mathrm{mm}$ increased in size) and/or gingival extended into the middle third of the anatomic crown. Grade 3, severe enlargement-nodular growth $>4 \mathrm{~mm}$ increased in size and/or gingival covering more than two thirds of the tooth crown ${ }^{(9)}$.

- Dental caries was assessed for the presence or absence of caries using the methods described for basic Oral Health Surveys by the World Health Organization "W.H.O. recommendations 1987" to calculate dental caries index DMF/def. For every child, the def and DMF indices were calculated separately ${ }^{(\mathbf{1 0})}$.

\section{Ethical consideration:}

An approval of the study was obtained from Ain Shams University Academic and Ethical Committee. Informed written consent was obtained from parents of all children participating before recruitment in the study after explaining the objectives of the work. This work has been carried out in accordance with The Code of Ethics of the World Medical Association (Declaration of Helsinki) for studies involving humans.

\section{Statistical analysis}

The collected data were coded, processed and analyzed using the SPSS (Statistical Package for Social Sciences) version 22 for Windows ${ }^{\circledR}$ (IBM SPSS Inc, Chicago, IL, USA). Data were tested for normal distribution using the Shapiro Walk test.

Qualitative data were represented as frequencies and relative percentages. Chi square test $\left(\chi^{2}\right)$ to calculate difference between two or more groups of qualitative variables. Quantitative data were expressed as mean $\pm \mathrm{SD}$ (Standard deviation). Independent samples t-test was used to compare between two independent groups of normally distributed variables (parametric data). $\mathrm{P}$ value $\leq 0.05$ was considered significant.

\section{RESULTS}

We studied 60 children with epilepsy on oral AED with age ranging from 6-12 years and the mean age was $9.77 \pm 1.64,46$ ( $40 \%$ were males). The mean body weight was $35.27 \pm 10.60$, the mean height was 126.90 $\pm 10.02 \mathrm{~cm}$, mean body mass index (BMI) was $21.39 \pm$ $4.11 \mathrm{~kg} / \mathrm{m}^{2}$, and the mean mid arm circumference was $24.37 \pm 2.46 \mathrm{~cm}$, there were 30 age- and sex-matched controls (Table 1).

Table (1): Comparison between the control and patients group regarding the demographic and anthropometric data 


\begin{tabular}{|c|c|c|c|c|}
\hline & & $\begin{array}{c}\text { Control group } \\
\text { No. }=\mathbf{3 0}\end{array}$ & $\begin{array}{l}\text { Patients group } \\
\text { No. }=60\end{array}$ & $\begin{array}{c}\text { Independent } \\
\text { t-test } \\
\text { P-value }\end{array}$ \\
\hline Age & $\begin{array}{l}\text { Mean } \pm \text { SD } \\
\text { Range }\end{array}$ & $\begin{array}{c}8.73 \pm 2.05 \\
6-12\end{array}$ & $\begin{array}{c}8.77 \pm 1.64 \\
6-12\end{array}$ & 0.352 \\
\hline Sex & $\begin{array}{l}\text { Male female } \\
\text { Female }\end{array}$ & $\begin{array}{l}14(46.7 \%) \\
16(53.3 \%) \\
\end{array}$ & $\begin{array}{l}24(40 \%) \\
36(60 \%) \\
\end{array}$ & 0.251 \\
\hline Weight & $\begin{array}{l}\text { Mean } \pm \text { SD } \\
\text { Range }\end{array}$ & $\begin{array}{c}36.93 \pm 11.91 \\
22-59\end{array}$ & $\begin{array}{c}35.27 \pm 10.60 \\
16-60\end{array}$ & 0.502 \\
\hline Height & $\begin{array}{l}\text { Mean } \pm \text { SD } \\
\text { Range }\end{array}$ & $\begin{array}{c}136.60 \pm 8.18 \\
125-151\end{array}$ & $\begin{array}{c}126.90 \pm 10.02 \\
100-140\end{array}$ & 0.000 \\
\hline BMI & $\begin{array}{l}\text { Mean } \pm \text { SD } \\
\text { Range }\end{array}$ & $\begin{array}{c}19.34 \pm 4.17 \\
13.64-27.665 \\
\end{array}$ & $\begin{array}{c}21.39 \pm 4.11 \\
14.876-30.612 \\
\end{array}$ & 0.029 \\
\hline MAC & $\begin{array}{l}\text { Mean } \pm \text { SD } \\
\text { Range }\end{array}$ & $\begin{array}{c}24.67 \pm 2.80 \\
20-30\end{array}$ & $\begin{array}{r}24.37 \pm 2.46 \\
20-28\end{array}$ & 0.604 \\
\hline
\end{tabular}

BMI body mass index; MAC mid arm circumference; *p value $<0.05$ was considered significant.

Comparison between the patients and control group in dental data:

The plaque index showed that the patients suffered from moderate to abundant plaque formation significantly more than control group ( $\mathrm{p}$ value 0.000 ). The def and DMF indices of all patients, which reflect dental caries showed that the patients suffered from dental caries significantly more than control group ( $p$ value 0.000). Gingival index of all patients, which reflects the gingival inflammation of all patients showed that the patients suffered from mild to moderate gingival inflammation, significantly more than control group ( $\mathrm{p}$ value 0.001). Gingival enlargement of all patients, which reflects the gingival enlargement showed that there was a mild to moderate and some severe gingival enlargement significantly more than control group ( $p$ value 0.000 ). There was no significant difference regarding dental hygiene between patients and controls ( $\mathrm{p}$ value 0.100) as shown in table (2).

Table (2): Comparison between the patients and control group in dental data

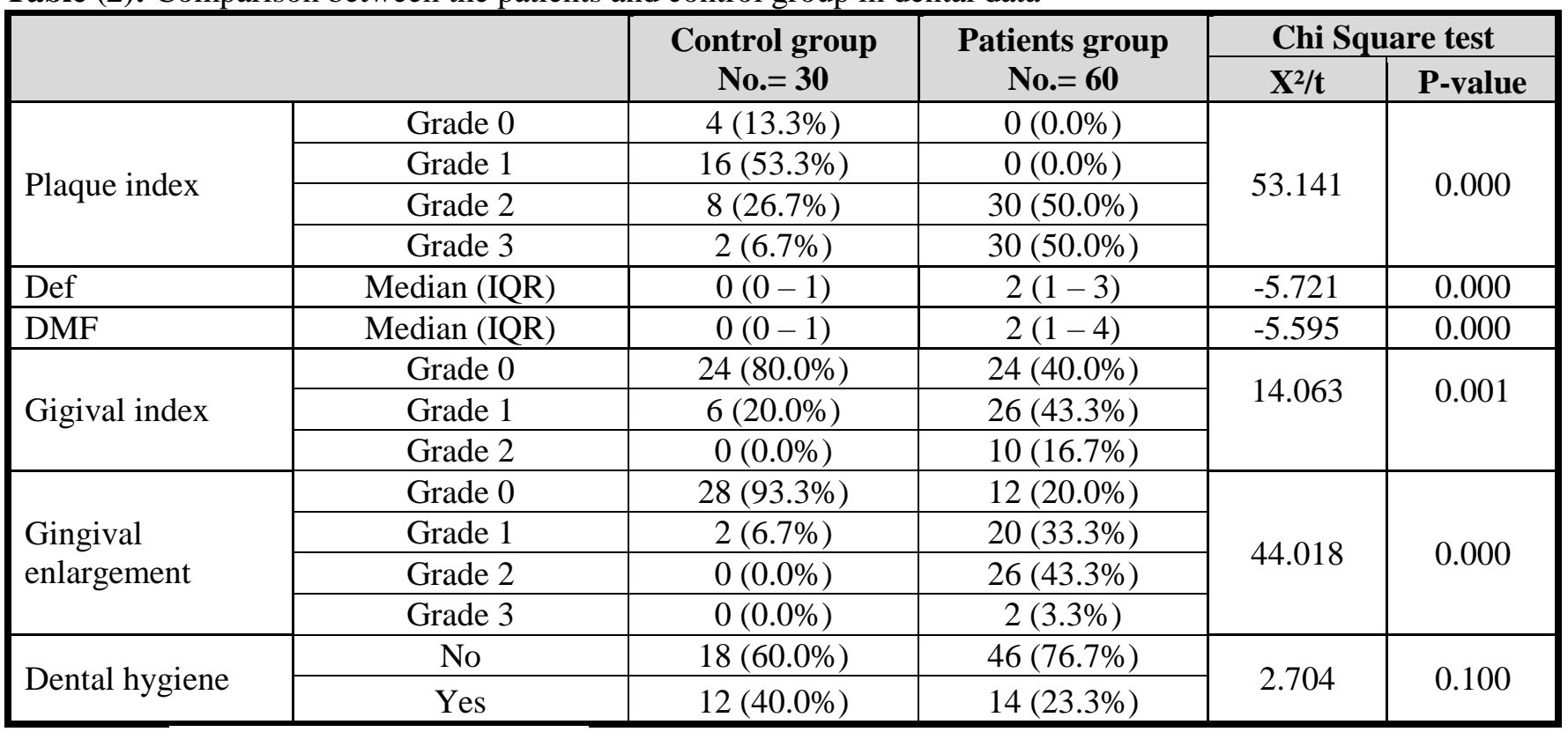

DMF index the decay-missing-filled index; def is equivalent to DMF index for primary dentation.

*p value less than 0.05 was considered significant, * Independent t-test was used. 
Comparison between the control, LEV and TPM groups in dental data:

The Plaque index was highly significant more plaque formation in the TPM and LEV groups than the control group $(\mathrm{p}<0.001)$ and there was no significant difference between the TPM and the LEV groups $(\mathrm{p}=$ $0.494)$. The def index which assessed dental caries in primary dentition showed a highly significant affected tooth more in both LEV and TPM groups than the control group, while TPM group showed significantly affected teeth than the LEV group. The DMF which assessed the dental caries in the permanent teeth showed highly significantly affected teeth more in both LEV and TPM groups than in the control group, while non-significant difference between TPM and LEV groups. The Gingival index which assessed gingival inflammation showed both LEV and TPM groups were highly significantly affected than the control group ( $\mathrm{p}$ value $<0.001$ ), while the LEV group was significantly affected than the TPM group $(\mathrm{p}=$ $0.002)$.

The Gingival enlargement index, which assessed gingival enlargement showed that both LEV and TPM groups were highly significantly affected than the control group $(\mathrm{p}<0.001)$, while there was no significant difference between the LEV and TPM groups $(\mathrm{p}=0.194)$ as shown in table $(3)$.

Table (3): Comparison between the control, levetiracetam and topiramate groups in dental data

\begin{tabular}{|c|c|c|c|c|c|c|}
\hline & & $\begin{array}{c}\text { Control } \\
\text { group }\end{array}$ & $\begin{array}{c}\text { Levetiracetam } \\
\text { group }\end{array}$ & $\begin{array}{c}\text { Topiramate } \\
\text { group }\end{array}$ & \multicolumn{2}{|c|}{$\begin{array}{c}\text { Chi-square } \\
\text { test }\end{array}$} \\
\hline & & No. $=\mathbf{3 0}$ & No. $=\mathbf{3 0}$ & No. $=\mathbf{3 0}$ & $\mathbf{X}^{2} / \mathbf{k}^{*}$ & P-value \\
\hline \multirow{4}{*}{ Plaque index } & Grade 0 & $4(13.3 \%)$ & $0(0.0 \%)$ & $0(0.0 \%)$ & \multirow{4}{*}{56.250} & \multirow{4}{*}{0.000} \\
\hline & Grade 1 & $16(53.3 \%)$ & $0(0.0 \%)$ & $0(0.0 \%)$ & & \\
\hline & Grade 2 & $8(26.7 \%)$ & $18(60.0 \%)$ & $12(40.0 \%)$ & & \\
\hline & Grade 3 & $2(6.7 \%)$ & $12(40.0 \%)$ & $18(60.0 \%)$ & & \\
\hline Def & Median (IQR) & $0(0-1)$ & $2(1-2)$ & $2(2-3)$ & $35.312 *$ & 0.000 \\
\hline DMF & Median (IQR) & $0(0-1)$ & $2(0-4)$ & $2(1-4)$ & $33.112 *$ & 0.000 \\
\hline \multirow{3}{*}{ Gingival index } & Grade 0 & $24(80.0 \%)$ & $12(40.0 \%)$ & $12(40.0 \%)$ & \multirow{3}{*}{21.150} & \multirow{3}{*}{0.000} \\
\hline & Grade 1 & $6(20.0 \%)$ & $10(33.3 \%)$ & $16(53.3 \%)$ & & \\
\hline & Grade 2 & $0(0.0 \%)$ & $8(26.7 \%)$ & $2(6.7 \%)$ & & \\
\hline \multirow{4}{*}{$\begin{array}{l}\text { Gingival } \\
\text { enlargement }\end{array}$} & Grade 0 & $28(93.3 \%)$ & $8(26.7 \%)$ & $4(13.3 \%)$ & \multirow{4}{*}{49.695} & \multirow{4}{*}{0.000} \\
\hline & Grade 1 & $2(6.7 \%)$ & $10(33.3 \%)$ & $10(33.3 \%)$ & & \\
\hline & Grade 2 & $0(0.0 \%)$ & $10(33.3 \%)$ & $16(53.3 \%)$ & & \\
\hline & Grade 3 & $0(0.0 \%)$ & $2(6.7 \%)$ & $0(0.0 \%)$ & & \\
\hline \multirow{2}{*}{ Dental hygiene } & No & $18(60.0 \%)$ & $22(73.3 \%)$ & $24(80.0 \%)$ & \multirow{2}{*}{3.029} & \multirow{2}{*}{0.220} \\
\hline & Yes & $12(40.0 \%)$ & $8(26.7 \%)$ & $6(20.0 \%)$ & & \\
\hline
\end{tabular}

DMF index the decay-missing-filled index; def is equivalent to DMF index for primary dentation.

*p value less than 0.05 was considered significant, *: Kruskal-Wallis test was used. 


\section{DISCUSSION}

We studied 60 epileptic children versus 30 normal children who served as control group. Epileptic children were divided into two groups. Group 1 included 30 epileptic children on Levetiracetam as monotherapy AED and group 2 included 30 epileptic children on Topiramate as monotherapy AED. We excluded from our study children with mental disorders or chronic diseases affecting dentation.

Regarding individual indices, we found that the Plaque index showed highly significant more plaque formation in the TPM and LEV groups than the control group ( $\mathrm{p}<0.001)$ and no significant difference between the TPM and the LEV groups $(p=0.494)$. The def index, which assessed dental caries in primary dentition showed a highly significantly affected teeth more in the LEV and TPM groups than in the control group, while showed significantly affected tooth of the TPM group than in the LEV group.

The DMF, which assessed the dental caries in the permanent teeth showed a highly significant affected teeth more in the LEV and TPM groups than in the control group while non-significant difference between the TPM and LEV groups. Gingival index, which assessed gingival inflammation showed that the LEV and TPM groups were highly significantly affected than the control group ( $\mathrm{p}<0.001)$, while the LEV group was significantly affected than the TPM group $(\mathrm{p}=0.002)$. Gingival enlargement index, which assessed gingival enlargement showed that the LEV and TPM groups were highly significantly affected than the control group $(\mathrm{p}<0.001)$, while there was no significant difference between the LEV and TPM groups $(p=0.194)$.

Side effects of AEDS were reported in few studies especially with the use of phenytoin (PHT). Some recent studies reported xerostomia, gingivitis and gingival overgrowth as common side effect of the AED drugs ${ }^{(11)}$. Few children even had glossitis among Indian children (57\% prevalence, age range 8-13 years) with epileptic disorders and receiving mono-drug therapy with phenytoin (PHT), at Post Graduate Institute of Medical Education and Research, Chandigarh (PGIMER) ${ }^{(12)}$.

Recent AEDS like Topiramate and Levetiracetam were not studied for their side effects on oral health in children in most of the previous studies. Little known up to date about the mechanisms by which AEDS lead to disturbances in oral health of children receiving AEDS for long-time to control epilepsy. Singh et al. ${ }^{(13)}$ found a positive correlation between decreased level of serum folate and increasing severity of gingival enlargement due to consumption of AED. They have even come to the conclusion that reduced serum folate level can even lead to early onset of oral side effects of AED.

Valproate is a broad-spectrum antiepileptic drug used as a drug of choice for almost three decades as mentioned by Brodie and Dichter ${ }^{(14)}$.

Irrespective of type of epilepsy including absence,
GTC seizure, and myoclonic seizures, it is considered best treatment options by the clinicians. Eeg-Olofsson $\boldsymbol{e t} \boldsymbol{a l} .^{(15)}$ surveyed the frequency of intraoral side effects in connection with sodium valproate treatment in epileptic children between 8 and 14 years old. Their results revealed no divergences in the treated as compared to the untreated individuals, which could be regarded as intraoral side effects deriving from the drug treatment.

Tan et al. ${ }^{(16)}$ studied 68 epileptic children treated with valproate and other non-valproate antiepileptic drugs compared to 50 controls. Gingival enlargement, gingival index, plaque index, and probing depth were measured to assess periodontal health. They found that patients in both the valproate and non-valproate groups showed significantly higher gingival enlargement, with significant differences regarding gingival enlargement in children treated with valproate

Joshi et al. ${ }^{(17)}$ in a cross-sectional observational study conducted in the department of Pedodontics and attached general hospital on a sample size of 120 participants with 60 healthy and 60 epileptic children between age 2 and 14 years. They reported that oral health status of participants was examined using oral hygiene simplified index and plaque index. They concluded that epileptic children under medication had poor oral hygiene and an increased risk for gingival enlargement as compared to their healthy counterparts.

The quality of life of epileptic children gets affected due to deterioration in their oral health along with systemic and social problems.

From a dental point of view children receiving AEDs were statistically significantly lower in all indices of oral health when compared to apparently healthy normal control children. Comparing the effects of individual AEDs, there were statistically significantly more serious side effects on oral health status in children receiving TPM more than children receiving LEV as monotherapy.

\section{CONCLUSION}

Recent AEDs like TPM and LEV showed significant alteration of oral health status in children receiving AEDs as monotherapy, and regular surveillance by a pediatric dental expert of the oral health is mandatory to improve their oral health and overall quality of life.

\section{Why this paper is important to pediatric dentists:}

- This study highlights the effects of recent AEDs on oral health.

- The importance of regular dental check up by pediatric dental expert for children on AEDs.

- Family education of epileptic children on regular oral hygiene to improve their oral

- health status and overall quality of life care.

\section{REFERENCES}


1. Camfield P, Camfield C (2015): Incidence, prevalence and aetiology of seizures and epilepsy in children. Epileptic Disord., 17 (2): 117-123.

2. Fisher R, Acevedo C, Arzimanoglou A et al. (2014): ILAE official report: a practical clinical definition of epilepsy. Epilepsia, 55 (4): 475-482.

3. Kothare S, Kaleyias J (2007): The adverse effects of antiepileptic drugs in children. Expert Opin Drug Saf., 6 (3): 251-265.

4. Cornacchio A, Burneo J, Aragon C (2011): The effects of antiepileptic drugs on oral health. J Can Dent Assoc., 77: $140-145$

5. Löe H (1967): The Gingival Index, the Plaque Index and the Retention Index Systems. J Periodontol., 38 (6): 610616.

6. Hong H, Trackman P (2002): Cytokine regulation of gingival fibroblast lysyl oxidase, collagen, and elastin. J Periodontol., 73 (2): 145-152.

7. Angelopoulos A, Goaz P (1972): Incidence of diphenylhydantoin gingival hyperplasia. Oral Surg Oral Med Oral Pathol., 34 (6): 898-906.

8. Miller C, Damm D (1992): Incidence of verapamilinduced gingival hyperplasia in a dental population. $\mathbf{J}$ Periodontol., 63 (5): 453-456.

9. Modéer T, Wondimu B (2000): Periodontal diseases in children and adolescents. Dent Clin North Am., 44 (3): 633-658

10. Plaka K, Ravindra K, Mor S et al. (2017): Risk factors and prevalence of dental fluorosis and dental caries in school children of North India. Environ Monit Assess., 189 (1): 40-46.

11. Ghafoor P, Rafeeq M, Dubey A (2014): Assessment of oral side effects of Antiepileptic drugs and traumatic orofacial injuries encountered in Epileptic children. J Int Oral Health, 6 (2): 126-128.

12. Prasad V, Chawla H, Goyal A et al. (2002): Incidence of phenytoin induced gingival overgrowth in epileptic children: A six month evaluation. J Indian Soc Pedod Prev Dent., 20: 73-80.

13. Nayyar A, Khan M, Vijayalakshmi K et al. (2014): Phenytoin, folic acid and gingival enlargement: Breaking myths. Contemp Clin Dent., 5 (1): 59-66.

14. Brodie M, Dichter M (1996): Antiepileptic drugs. N Engl J Med., 334 (7): 168-175.

15. Eeg-Olofsson O, Lundström A, Hamp S (1983): Oral state of children with epilepsy on treatment with sodium valproate. Scand J Dent Res., 91 (3): 219-223.

16. Tan H, Gürbüz T, Dağsuyu I (2004): Gingival enlargement in children treated with antiepileptics. J Child Neurol., 19 (12): 958-963.

17. Joshi N, Deshpande A, Deshpande N et al. (2017): Comparative evaluation of oral hygiene status and gingival enlargement among epileptic and healthy children as related to various antiepileptic drugs. J Indian Soc Periodontol., 21 (2): 125-129. 